See discussions, stats, and author profiles for this publication at: https://www.researchgate.net/publication/288579511

\title{
Impacts of meloxicam administration before temporary calf weaning on physiological and reproductive responses of Bos indicus beef cows
}

Article in Journal of Animal Science · December 2015

DOI: $10.2527 /$ jas $2015-9222$

CITATIONS

0

9 authors, including:

Reinaldo Fernandes Cooke

Texas A\&M University

204 PUBLICATIONS 1,524 CITATIONS

SEE PROFILE

Rodrigo S. Marques

Oregon State University

82 PUBLICATIONS 245 CITATIONS

SEE PROFILE

Some of the authors of this publication are also working on these related projects:

\section{READS}

52

Rafael Cipriano

Centro Universitário Salesiano de São Paulo

29 PUBLICATIONS 103 CITATIONS

SEE PROFILE

David W Bohnert

Oregon State University

136 PUBLICATIONS 1,448 CITATIONS

SEE PROFILE

Effects of temperament on physiological, productive, and reproductive responses in beef cows View project

Leishmaniose visceral canina em Araçatuba (SP) e sua relação com características de cães e seus proprietários: uma análise transversal e espacial utilizando uma abordagem geoestatística View project 


\title{
Impacts of meloxicam administration before temporary calf weaning on physiological and reproductive responses of Bos indicus beef cows 1
}

\author{
R. F. Cooke, ${ }^{* 2}$ R. F. G. Peres, $\dagger+$ R. S. Cipriano, $§$ T. A. Guarnieri Filho, ${ }^{*} \dagger$ \\ R. S. Marques, * M. C. Rodrigues, ${ }^{*} \uparrow$ R. S. Carvalho, $\neq$ D. W. Bohnert, $*$ and J. L. M. Vasconcelos $\uparrow$ \\ *Eastern Oregon Agricultural Research Center, Oregon State University, \\ Burns 97720; †Faculdade de Medicina Veterinária e Zootecnia, Universidade Estadual Paulista, \\ Campus de Botucatu, SP, Brazil 18618-970; \$Agropecuária Fazenda Brasil, Nova Xavantina, MT, Brazil \\ 78690-000; and §Centro Universitário Católico Salesiano Auxilium- UniSalesiano, Araçatuba, SP, Brazil 16016-500
}

\begin{abstract}
The objective of this experiment was to evaluate temperament, physiological, and reproductive variables in Bos indicus beef cows assigned to an estrus synchronization + timed AI protocol including eCG administration, 48-h temporary calf weaning (TCW), or $\mathrm{TCW}+$ meloxicam administration. A total of 943 lactating, multiparous, nonpregnant Nelore cows, allocated into 8 groups of approximately 120 cows each, were assigned to the experiment. Groups were maintained in individual pastures and assigned to the following estrus synchronization + timed AI protocol: a 2-mg injection of estradiol benzoate and an intravaginal progesteronereleasing device (CIDR) on d 0 , a $12.5-\mathrm{mg}$ injection of $\mathrm{PGF}_{2 \alpha}$ on $\mathrm{d} 7$, CIDR removal in addition to a 0.6mg injection of estradiol cypionate on $\mathrm{d} 9$, and timed AI on $\mathrm{d} 11$. Within each group, cows were randomly assigned on d 9 to 1 ) TCW from d 9 to 11 (TCW-CON; $n=317), 2$ ) no TCW and a 300-IU injection of eCG on d 9 (NOTCW; $n=311$ ), and 3) TCW-CON in addition to meloxicam administration (intramuscular; $0.5 \mathrm{mg} / \mathrm{kg}$ $\mathrm{BW}$ ) on d 9 (TCW-MEL; $n=315$ ). Cow BW and BCS were assessed on $\mathrm{d} 0$. On d 9 and 11, blood samples were collected, and cow temperament was evaluated via chute score and exit velocity. Pregnancy status was
\end{abstract}

verified $30 \mathrm{~d}$ after timed AI via transrectal ultrasonography. No treatment differences were detected $(P \geq 0.23)$ for cow age, days postpartum, BW, and BCS on d 0 of the estrus synchronization + timed AI protocol. No treatment effects were detected $(P \geq 0.41)$ for any of the temperament variables evaluated. A treatment $\times$ day interaction was detected $(P=0.02)$ for serum cortisol concentrations, which were similar $(P=0.55)$ between treatments on $\mathrm{d} 9$ but greater $(P \leq 0.05)$ in TCW-CON and TCW-MEL compared with NOTCW cows on d 11. No treatment effects were detected $(P=0.90)$ for serum haptoglobin concentrations, which decreased from d 9 to 11 in all treatments (day effect; $P<0.01$ ). No treatment differences were detected $(P=0.84)$ for pregnancy rates to timed AI. In summary, TCW during estrus synchronization did not impact temperament or serum haptoglobin concentrations in $B$. indicus beef cows but increased serum cortisol concentrations compared with cows not assigned to TCW, although such an outcome was not sufficient to impact pregnancy rates to timed AI. Moreover, administration of meloxicam did not alleviate the TCW-induced increase in serum cortisol concentrations and failed to benefit pregnancy rates to timed AI in B. indicus beef cows.

Key Words: artificial insemination, beef cows, meloxicam, reproduction, temporary calf weaning

\footnotetext{
${ }^{1}$ The Fundação de Amparo à Pesquisa do Estado de São Paulo (São Paulo, Brazil) provided financial support for R. F. Cooke (grant number 2014/19485-7). Appreciation is expressed to M. R. Bastos (Ourofino Saúde Animal), J. Furlan, C. Fleury, H. Graff (Agropecuária Fazenda Brasil), and all the staff from Agropecuária Fazenda Brasil for their assistance.

${ }^{2}$ Corresponding author: reinaldo.cooke@oregonstate.edu

Received April 20, 2015.

Accepted November 6, 2015.
}

\section{INTRODUCTION}

Weaning stimulates stress-related temperament and physiological changes in calves and cows (Whisnant et al., 1985; von Keyserlingk and Weary, 2007), such as inflammatory and acute-phase protein responses (Arthington et al., 2005), known to impair reproductive performance in beef females (Cooke et 
al., 2009). However, inclusion of temporary calf weaning (48 h; TCW) in estrus synchronization protocols based on estradiol + progesterone increased pregnancy rates to timed AI in Bos indicus beef cows (Sá Filho et al., 2009), given that TCW promotes adequate LH secretion for follicular growth and ovulation (Williams et al., 1983; Edwards, 1985). One alternative to prevent the stress associated with TCW during estrus synchronization but still enhance preovulatory follicular development is to replace TCW with a single eCG administration (Kuran et al., 1996). Nevertheless, Sá Filho et al. (2009) reported similar pregnancy rates to timed AI in $B$. indicus cows assigned to $\mathrm{TCW}$, eCG administration, or both. Therefore, strategies that alleviate stress-induced responses in $B$. indicus beef cows receiving TCW may further improve pregnancy rates to timed AI compared with conventional TCW or eCG treatment.

Administration of meloxicam, a nonsteroidal antiinflammatory drug, to cattle exposed to stressful procedures alleviated the resultant inflammatory reactions (Guarnieri Filho et al., 2014; Van Engen et al., 2014). Moreover, meloxicam has a half-life of $28 \mathrm{~h}$ and remains in the circulation for $5 \mathrm{~d}$ after a single administration to cattle (Van Engen et al., 2014). On the basis of this rationale, we hypothesized that meloxicam administration to beef cows mitigates TCW-induced inflammatory reactions and further improves pregnancy rates to timed AI. Therefore, this experiment evaluated temperament, physiological, and reproductive variables in $B$. indicus beef cows assigned to an estrus synchronization + timed AI protocol including eCG administration, $\mathrm{TCW}$, or TCW + meloxicam administration.

\section{MATERIALS AND METHODS}

This experiment was conducted from January to February 2015 on a commercial cow-calf operation located in Nova Xavantina, Brazil. The animals utilized herein were cared for in accordance with the practices outlined in the Guide for the Care and Use of Agricultural Animals in Agricultural Research and Teaching (Federation of Animal Science Societies, 2010).

\section{Animals and Treatments}

A total of 943 lactating, multiparous, nonpregnant Nelore cows (age $=99 \pm 2 \mathrm{mo}$, days postpartum $=51.4$ $\pm 0.3 \mathrm{~d}$; $\mathrm{BW}=430 \pm 2 \mathrm{~kg}$, and $\mathrm{BCS}=5.34 \pm 0.03$, according to Wagner et al. [1988] and assessed by a single technician) were assigned to the experiment. After calving, cows were allocated into 8 groups of approximately 120 cows each (range $=114$ to 123 cows/group) according to the general management scheme of the operation, and this arrangement was maintained throughout the experimental period. Groups were maintained in individual Brachiaria brizantha pastures (average stocking rate $=1$ cow-calf pair/ha) with ad libitum access to water and a commercial mineral-vitamin mix (DSM Produtos Nutricionais Brasil, São Paulo, Brazil). All groups were assigned to the same estrus synchronization + timed AI protocol; Meneghetti et al., 2009; d 0 to 11). More specifically, cows received a 2-mg injection (intramuscular [i.m.]) of estradiol benzoate (Gonadiol; Zoetis, São Paulo, Brazil) and an intravaginal progesterone releasing device (CIDR, originally containing $1.9 \mathrm{~g}$ of progesterone; Zoetis) on d 0, a 12.5-mg injection (i.m.) of $\mathrm{PGF}_{2 \alpha}$ (Lutalyse; Zoetis) on d 7, CIDR removal in addition to a 0.6-mg injection (i.m.) of estradiol cypionate (ECP; Zoetis) on d 9, and timed AI on d 11. Within each group, cows were randomly assigned on $\mathrm{d} 9$ of the estrus synchronization + timed AI protocol to 1 of 3 treatments: 1) 48-h TCW from d 9 (immediately after CIDR removal and ECP injection) until after timed AI on d 11 (TCW-CON; $n=317$ ), 2) no TCW and a 300-IU injection (i.m.) of eCG (Novormon, Zoetis) administered concurrently with ECP on d 9 (NOTCW; $n=311)$, and 3 ) the same as TCW-CON, with the addition of meloxicam administration (11-mL i.m. injection of Maxicam 2\%; Ourofino Saúde Animal, Cravinhos, Brazil) concurrently with ECP on d 9 (TCW-MEL; $n=315$ ).

Within each group, cows were inseminated by 1 of 2 technicians with semen from 2 different sires. The proportion of cows inseminated by each technician, sire, and the combination of technician and sire were balanced within each group. From d 9 to d 11, TCW-CON and TCW-MEL cows returned to pasture and had no visual contact with their calves, which remained inside the working facility with ad libitum access to water and a pelletized concentrate (DSM Produtos Nutricionais Brasil), while NOTCW cows and their calves were maintained in the same pasture as TCW-CON and TCW-MEL cows. After timed AI on d 11, TCW-CON and TCW-MEL cows were reunited with their respective calves, and all cow-calf pairs returned to pasture. The meloxicam dose utilized herein was based on the average BW of the herd on $\mathrm{d} 0(430 \pm 2 \mathrm{~kg})$ to result in $0.5 \mathrm{mg}$ of meloxicam administered per kilogram of cow $\mathrm{BW}$, which is the injectable dose suggested by the manufacturer and used in previous research with dairy cows (Amiridis et al., 2009; Erdem and Guzeloglu, 2010).

\section{Sampling}

Cow BW and BCS were assessed on $\mathrm{d} 0$ of the estrus synchronization + timed AI protocol. Cow temperament was evaluated, and blood samples were collected immediately before treatment application on $\mathrm{d} 9$ and immediately before timed AI on d 11. Pregnancy 
status was verified $30 \mathrm{~d}$ after timed AI by detecting a viable conceptus with transrectal ultrasonography (5.0$\mathrm{MHz}$ transducer; 500V, Aloka, Wallingford, CT). Cows were not exposed to bulls or to additional AI services between timed AI on $\mathrm{d} 11$ and pregnancy evaluation.

Cow temperament was assessed by chute score and exit velocity as previously described by Cooke et al. (2011a) by a single technician. Chute score was assessed on the basis of a 5-point scale where $1=$ calm with no movement, 2 = restless movements, $3=$ frequent movement with vocalization, $4=$ constant movement, vocalization, shaking of the chute, and $5=$ violent and continuous struggling. Exit velocity was assessed by determining the speed of the cow exiting the squeeze chute by measuring rate of travel over a 1.8-m distance with an infrared sensor (FarmTek Inc., North Wylie, TX). In addition, cows were divided in quintiles within each group according to their exit velocity and were assigned a score from 1 to 5 (exit score; 1 = cows within the slowest quintile, $5=$ cows within the fastest quintile). Individual temperament scores were calculated by averaging cow chute score and exit score.

Blood samples were collected from either the coccygeal vein or artery into commercial blood collection tubes (Vacutainer, $10 \mathrm{~mL}$; Becton Dickinson, Franklin Lakes, NJ). After collection, blood samples were placed immediately on ice, allowed to clot for 24 $\mathrm{h}$ at $4^{\circ} \mathrm{C}$, centrifuged at $3,000 \times g$ at room temperature for $15 \mathrm{~min}$ for serum collection, and stored at $-20^{\circ} \mathrm{C}$. Serum cortisol concentrations were determined using a chemiluminescent enzyme immunoassay (Immulite 1000; Siemens Medical Solutions Diagnostics, Los Angeles, CA). Serum haptoglobin concentrations were determined according to the colorimetric procedure described by Cooke and Arthington (2013). The intra- and interassay CV were, respectively, 3.0\% and $2.1 \%$ for cortisol and $2.2 \%$ and $7.8 \%$ for haptoglobin.

\section{Statistical Analysis}

Quantitative (cow age, BCS, BW, days postpartum, serum variables, and temperament variables) and binary (pregnancy outcomes) data were analyzed, respectively, with the MIXED and GLIMMIX procedures of SAS (SAS Inst. Inc., Cary, NC; version 9.3) and the Satterthwaite approximation to determine the denominator degrees of freedom for the tests of fixed effects, using cow as the experimental unit and cow(treatment $x$ group) as the random variable. The model statement used for analysis of cow age, days postpartum, BW, and BCS on $\mathrm{d} 0$ contained the effects of treatment, group, and the resultant interaction. The model statement used for analysis of temperament and serum variables contained the effects of treatment, day, group, and all resultant in-
Table 1. Age, days postpartum, BW, and BCS of $B$. indicus beef cows assigned to an estrus synchronization protocol including temporary calf weaning (TCW-CON; $n=317)$, TCW-CON + meloxicam administration (TCW-MEL; $n=315$ ), or no temporary calf weaning (NOTCW; $n=311)^{1}$

\begin{tabular}{lccclc}
\hline \hline Item $^{2}$ & NOTCW & TCW-CON & TCW-MEL & SEM & $P$-value \\
\hline Age, mo & 101.7 & 97.4 & 98.5 & 2.8 & 0.52 \\
Days postpartum & 51.3 & 51.8 & 50.9 & 0.5 & 0.40 \\
BW, kg & 430 & 427 & 433 & 3 & 0.23 \\
BCS & 5.34 & 5.27 & 5.39 & 0.06 & 0.38 \\
\hline
\end{tabular}

${ }^{1}$ Cows were assigned to an estrus synchronization + timed AI protocol (Meneghetti et al., 2009) from d 0 to 11 . On d 9, cows were randomly assigned to 1) TCW-CON $=48$-h TCW from d 9 until after timed AI on d $11,2)$ NOTCW $=$ no TCW and a 300-IU injection (intramuscular [i.m.]) of eCG (Novormon, Zoetis, São Paulo, Brazil) administered on d 9, and 3) TCW-MEL $=\mathrm{TCW}+$ meloxicam administration $(11-\mathrm{mL}$ i.m. injection of Maxicam 2\%, Ourofino Saúde Animal, Cravinhos, Brazil) on d 9.

${ }^{2} \mathrm{Cow}$ age, days postpartum, BW, and BCS (Wagner et al., 1988; assessed by a single technician) were recorded on $\mathrm{d} 0$.

teractions. The specified term for the repeated statement was day, cow(treatment $\times$ group) was the subject, and the covariance structure utilized for all repeated statements was autoregressive, which provided the best fit for these analyses according to the Akaike information criterion. The model statement used for analysis of pregnancy rates to timed AI contained the effects of treatment, group, and the resultant interaction in addition to sire(group) and AI technician(group) as random variables. Significance was set at $P \leq 0.05$, and tendencies were determined if $P>0.05$ and $\leq 0.10$. Results were separated using PDIFF and are reported as least squares means according to the main treatment effect if no interactions were significant or according to the highest-order interaction detected that contained the effect of treatment.

\section{RESULTS AND DISCUSSION}

No treatment differences were detected $(P \geq 0.23)$ for cow age, days postpartum, BW, and BCS on $\mathrm{d}$ 0 of the estrus synchronization + timed AI protocol (Table 1), indicating that any treatment effects reported herein were independent of these variables. Further, all cows utilized herein were in adequate nutritional status according to their BCS and within the recommended voluntary waiting period for $B$. indicus - influenced cattle to optimize pregnancy rates to timed AI (Cooke et al., 2009) and maintain a 365-d calving interval (Vasconcelos et al., 2014).

No treatment effects were detected $(P \geq 0.41)$ for any of the temperament variables evaluated (Table 2 ). The process of separating cows from their calves, whether temporary or permanent, is known to impact cow behavioral traits, including increased vocaliza- 
Table 2. Temperament measurements of B. indicus beef cows assigned to an estrus synchronization protocol including temporary calf weaning (TCW-CON; $n=317)$, TCW-CON + meloxicam administration (TCW-MEL; $n=315$ ), or no temporary calf weaning (NOTCW; $n=311)^{1}$

\begin{tabular}{lccccc}
\hline \hline Item $^{2}$ & NOTCW TCW-CON & TCW-MEL & SEM & $P$-value \\
\hline Chute score & & & & & \\
d 9 & 1.94 & 1.92 & 1.93 & 0.04 & 0.82 \\
d 11 & 1.96 & 1.95 & 1.95 & 0.04 & 0.98 \\
Exit velocity, m/s & & & & & \\
$\quad$ d 9 & 2.11 & 2.14 & 2.17 & 0.05 & 0.73 \\
d 11 & 2.23 & 2.32 & 2.24 & 0.05 & 0.41 \\
Exit score & & & & & \\
d 9 & 2.98 & 3.00 & 3.04 & 0.08 & 0.86 \\
d 11 & 3.00 & 3.00 & 3.02 & 0.08 & 0.98 \\
Temperament score & & & & & \\
d 9 & 2.46 & 2.46 & 2.50 & 0.05 & 0.85 \\
d 11 & 2.48 & 2.48 & 2.48 & 0.05 & 0.99 \\
\hline
\end{tabular}

${ }^{1}$ Cows were assigned to an estrus synchronization + timed AI protocol (Meneghetti et al., 2009) from d 0 to 11. On d 9, cows were randomly assigned to 1) TCW-CON $=48$-h TCW from d 9 until after timed AI on d $11,2) \mathrm{NOTCW}=$ no TCW and a 300-IU injection (intramuscular [i.m.]) of eCG (Novormon, Zoetis, São Paulo, Brazil) administered on d 9, and 3) TCW-MEL $=\mathrm{TCW}+$ meloxicam administration $(11-\mathrm{mL}$ i.m. injection of Maxicam 2\%, Ourofino Saúde Animal, Cravinhos, Brazil) on d 9.

${ }^{2}$ Temperament was assessed as described by Cooke et al. (2011a).

tion and physical activity (von Keyserlingk and Weary, 2007). Nevertheless, the impacts of TCW on cow temperament during the estrus synchronization protocol still warranted investigation, given that temperament has been shown to influence productive and reproductive performance in cattle (Cooke et al., 2009, 2011a, 2012a). Using this rationale, we theorized that TCW would increase cow excitement during handling as evidence that TCW causes stress-induced temperament changes in $B$. indicus beef cows. However, the lack of treatment effects on cow temperament reported herein indicates that the TCW process was not sufficient to alter cow temperament during handling from $\mathrm{d} 9$ to 11 .

A treatment $\times$ day interaction was detected $(P=$ 0.02 ) for serum cortisol. On d 9, serum cortisol concentrations were similar $(P=0.55)$ between treatments; however, serum cortisol concentrations were greater $(P \leq$ 0.05 ) in TCW-CON and TCW-MEL cows compared with NOTCW cohorts on d 11 (Table 3). In addition, serum cortisol concentrations increased from d 9 to 11 in TCW-CON and TCW-MEL cows (day effect, $P<0.01$ ) but not in NOTCW cows (day effect, $P=0.22$; Table 3 ). These results corroborate our hypothesis and previous research (Whisnant et al., 1985) reporting that TCW elicits a neuroendocrine stress response in beef cows. However, meloxicam administration did not prevent or alleviate the TCW-induced cortisol response, given that serum corti-
Table 3. Serum concentrations of cortisol and haptoglobin and pregnancy rates in $B$. indicus beef cows assigned to an estrus synchronization protocol including temporary calf weaning (TCW-CON; $n=317$ ), TCW-CON + meloxicam administration (TCW-MEL; $n=315$ ), or no temporary calf weaning (NOTCW; $n=311)^{1}$

\begin{tabular}{cccccc}
\hline \hline Item & NOTCW & TCW-CON & TCW-MEL & SEM & $P$-value \\
\hline Cortisol, ng/mL & & & & & \\
d 9 & 37.8 & 38.2 & 39.3 & 1.1 & 0.55 \\
d 11 & $38.9^{\mathrm{a}}$ & $41.8^{\mathrm{b}}$ & $43.9^{\mathrm{b}}$ & 1.1 & $<0.01$ \\
Haptoglobin, ng/mL & & & & & \\
d 9 & 0.354 & 0.355 & 0.324 & 0.027 & 0.66 \\
d 11 & 0.254 & 0.281 & 0.296 & 0.027 & 0.54 \\
Pregnancy rates, ${ }^{2} \%$ & 46.6 & 45.8 & 44.3 & 3.6 & 0.84 \\
& $(145 / 311)$ & $(145 / 317)$ & $(139 / 315)$ & & \\
\hline
\end{tabular}

a,b Within rows, values with different letters differ $(P<0.05)$.

${ }^{1}$ Cows were assigned to an estrus synchronization + timed AI protocol (Meneghetti et al., 2009) from d 0 to 11 . On d 9, cows were randomly assigned to 1) TCW-CON $=48$-h TCW from d 9 until after timed AI on d $11,2)$ NOTCW $=$ no TCW and a 300-IU injection (intramuscular [i.m.]) of eCG (Novormon, Zoetis, São Paulo, Brazil) administered on d 9, and 3) TCW-MEL $=$ TCW + meloxicam administration (11-mL i.m. injection of Maxicam 2\%, Ourofino Saúde Animal, Cravinhos, Brazil) on d 9.

${ }^{2}$ Pregnancy status to timed AI was verified by detecting a viable conceptus with transrectal ultrasonography $(5.0-\mathrm{MHz}$ transducer; $500 \mathrm{~V}$, Aloka, Wallingford, CT) on d 41. Values reported within parentheses correspond to number of pregnant cows/total cows assigned to timed AI.

sol concentrations between TCW-CON and TCW-MEL cows were similar $(P=0.24)$ on d 11. Guarnieri Filho et al. (2014) and Van Engen et al. (2014) also reported that meloxicam administration to transported feeder cattle did not impact circulating cortisol concentrations after transport and feedlot entry. Accordingly, meloxicam is known to inhibit cyclooxygenase- 2 activity and subsequent production of PG and other inflammatory compounds (Griswold and Adams, 1996), whereas its impacts on adrenal corticoid synthesis, if any, still require investigation (Van Engen et al., 2014).

No treatment effects were detected $(P=0.90)$ for serum haptoglobin concentrations (Table 3 ). The stress caused by cow and calf separation elicits inflammatory responses including the acute-phase protein reaction, which results in nonspecific increases in plasma concentrations of acute-phase proteins such as haptoglobin (Arthington et al., 2005). In fact, the acute-phase protein reaction can be activated by several weaning stressors, including altered temperament (Francisco et al., 2012), elevated cortisol concentrations (Cooke and Bohnert, 2011; Cooke et al., 2012b), and potential decreases in cow DM and water intake during TCW (von Keyserlingk and Weary, 2007; Marques et al., 2012). Nevertheless, the vast majority of research evaluating the impacts of weaning on inflammatory and acute-phase protein reactions focused on the calf (Arthington et al., 2005, 2008; Cooke et al., 2011b), and little is known about its impacts 
on the cow. In the present experiment, the lack of treatment effects and the fact that serum haptoglobin concentrations decreased from d 9 to 11 in all treatments (day effect, $P<0.01$; Table 3 ) suggest that TCW did not stimulate an acute-phase protein reaction. Moreover, the lack of TCW-induced acute-phase protein reaction rendered meloxicam administration unnecessary, which may explain the similar serum haptoglobin concentrations between TCW-CON and TCW-MEL cows. Perhaps the stress-related responses elicited by TCW, such as serum cortisol, were not sufficient to stimulate an acute-phase protein reaction. One can also speculate that the sampling schedule adopted herein was not adequate to properly assess TCW-induced serum haptoglobin responses. However, circulating haptoglobin concentrations are increased from 24 to $72 \mathrm{~h}$ in beef calves exposed to the stress of weaning and road transport (Arthington et al., 2008; Araujo et al., 2010; Francisco et al., 2012). To our knowledge, this is the first research effort that evaluated serum haptoglobin concentrations in B. indicus cows on TCW; therefore, additional research is warranted to further understand this subject.

No treatment differences were detected $(P=0.84)$ for pregnancy rates to timed AI (Table 3 ). The rationale for this experiment was 1) TCW would increase cow excitement and serum cortisol concentrations (Whisnant et al., 1985; von Keyserlingk and Weary, 2007) during the estrus synchronization process, which in turn would stimulate an acute-phase protein reaction known to impair reproductive performance of $B$. indicus beef cows (Arthington et al., 2005; Cooke et al., 2009), and 2) meloxicam administration at the beginning of TCW would alleviate this latter outcome (Guarnieri Filho et al., 2014; Van Engen et al., 2014) and further improve pregnancy rates to timed AI compared with conventional TCW or eCG administration. This rationale was based on the premise that elevated cortisol and inflammatory compounds are known to directly impair mechanisms associated with fertility in cattle, such as synthesis and activity of $\mathrm{GnRH}$, gonadotropins, and estradiol (Peter et al., 1989; Dobson et al., 2000; Williams et al., 2001). Accordingly, Cooke et al. (2009) reported a negative association among plasma cortisol and haptoglobin concentrations at the beginning of a 90-d breeding season with the probability of $B$. indicus-influenced cows to become pregnant. In the present experiment, our hypothesis was partially accepted because TCW-CON and TCW-MEL cows had greater cortisol concentrations on d 11 compared with NOTCW cows, despite the lack of treatment effects on pregnancy rates to timed AI. Perhaps the magnitude of cortisol differences among TCW-CON and TCW-MEL vs. NOTCW cows on d 11 was not only insufficient to increase serum haptoglobin concentrations in TCW-receiving cows as previously mentioned but also insufficient to yield differences in pregnancy rates to timed AI. Nevertheless, the similar pregnancy rates to timed AI among treatments support the results reported by Sá Filho et al. (2009) and summarized by Vasconcelos et al. (2014); estrus synchronization + timed AI protocols based on progesterone and estradiol can be associated with either TCW or eCG to enhance reproductive performance of $B$. indicus cows.

In summary, results from this experiment indicate that inclusion of TCW into an estrus synchronization protocol based on estradiol and progesterone did not impact temperament or serum haptoglobin concentrations in $B$. indicus beef cows but increased serum cortisol concentrations compared with cohorts not assigned to TCW, although this outcome was not sufficient to impact pregnancy rates to timed AI. In addition, administration of meloxicam did not alleviate the TCW-induced increase in serum cortisol concentrations and failed to improve pregnancy rates to timed $\mathrm{AI}$ in $B$. indicus beef cows.

\section{LITERATURE CITED}

Amiridis, G. S., T. Tsiligianni, E. Dovolou, C. Rekkas, D. Vouzaras, and I. Menegatos. 2009. Combined administration of gonadotropin-releasing hormone, progesterone, and meloxicam is an effective treatment for the repeat-breeder cow. Theriogenology 72:542-548. doi:10.1016/j.theriogenology.2009.04.010.

Araujo, D. B., R. F. Cooke, G. R. Hansen, C. R. Staples, and J. D. Arthington. 2010. Effects of rumen-protected polyunsaturated fatty acid supplementation on performance and physiological responses of growing cattle following transportation and feedlot entry. J. Anim. Sci. 87:4125-4132.

Arthington, J. D., X. Qiu, R. F. Cooke, J. M. B. Vendramini, D. B. Araujo, C. C. Chase Jr., and S. W. Coleman. 2008. Effects of pre-shipping management on measures of stress and performance of beef steers during a feedlot receiving period. J. Anim. Sci. 86:2016-2023. doi:10.2527/jas.2008-0968.

Arthington, J. D., J. W. Spears, and D. C. Miller. 2005. The effect of early weaning on feedlot performance and measures of stress in beef calves. J. Anim. Sci. 83:933-939.

Cooke, R. F., and J. D. Arthington. 2013. Concentrations of haptoglobin in bovine plasma determined by ELISA or a colorimetric method based on peroxidase activity. J. Anim. Physiol. Anim. Nutr. 97:531-536. doi:10.1111/j.1439-0396.2012.01298.x.

Cooke, R. F., J. D. Arthington, D. B. Araujo, and G. C. Lamb. 2009. Effects of acclimation to human interaction on performance, temperament, physiological responses, and pregnancy rates of Brahman-crossbred cows. J. Anim. Sci. 87:4125-4132. doi:10.2527/jas.2009-2021.

Cooke, R. F., and D. W. Bohnert. 2011. Bovine acute-phase response following corticotrophin-release hormone challenge. J. Anim. Sci. 89:252-257. doi:10.2527/jas.2010-3131.

Cooke, R. F., D. W. Bohnert, B. I. Cappellozza, C. J. Mueller, and T. DelCurto. 2012a. Effects of temperament and acclimation to handling on reproductive performance of Bos taurus beef females. J. Anim. Sci. 90:3547-3555. doi:10.2527/jas.2011-4768.

Cooke, R. F., D. W. Bohnert, M. Meneghetti, T. C. Losi, and J. L. M. Vasconcelos. 2011a. Effects of temperament on pregnancy rates to fixed-timed AI in Bos indicus beef cows. Livest. Sci. 142:108-113. doi:10.1016/j.livsci.2011.06.024. 
Cooke, R. F., D. W. Bohnert, P. Moriel, B. W. Hess, and R. R. Mills. 2011b. Effects of polyunsaturated fatty acid supplementation on forage digestibility, performance, and physiological responses of feeder cattle. J. Anim. Sci. 89:36773689. doi:10.2527/jas.2010-3515.

Cooke, R. F., J. A. Carroll, J. Dailey, B. I. Cappellozza, and D. W. Bohnert. 2012b. Bovine acute-phase response following different doses of corticotrophin-release hormone challenge. J. Anim. Sci. 90:2337-2344. doi:10.2527/jas.2011-4608.

Dobson, H., A. Y. Ribadu, K. M. Noble, J. E. Tebble, and W. R. Ward. 2000. Ultrasonography and hormone profiles of adrenocorticotrophic hormone (ACTH)-induced persistent ovarian follicles (cysts) in cattle. J. Reprod. Fertil. 120:405-410. doi:10.1530/reprod/120.2.405.

Edwards, S. 1985. The effects of short term calf removal on pulsatile LH secretion in the postpartum beef cow. Theriogenology 23:777-785. doi:10.1016/0093-691X(85)90153-0.

Erdem, H., and A. Guzeloglu. 2010. Effect of meloxicam treatment during early pregnancy in Holstein heifers. Reprod. Domest. Anim. 45:625-628

Federation of Animal Science Societies. 2010. Guide for the care and use of agricultural animals in agricultural research and teaching. 3rd ed. Fed. Anim. Sci. Soc., Savoy, IL.

Francisco, C. L., R. F. Cooke, R. S. Marques, R. R. Mills, and D. W. Bohnert. 2012. Effects of temperament and acclimation to handling on feedlot performance of Bos taurus feeder cattle originated from a rangeland-based cow-calf system. J. Anim. Sci. 90:5067-5077. doi:10.2527/jas.2012-5447.

Griswold, D. E., and J. L. Adams. 1996. Constitutive cyclooxygenase (COX-1) and inducible cyclooxygenase (COX2): Rationale for selective inhibition and progress to date. Med. Res. Rev. 16:181-206. doi:10.1002/(SICI)10981128(199603)16:2<181::AID-MED3>3.0.CO;2-X.

Guarnieri Filho, T. A., R. F. Cooke, B. I. Cappellozza, M. M. Reis, R. S. Marques, and D. W. Bohnert. 2014. Effects of meloxicam administration on physiological and performance responses of transported feeder cattle. J. Anim. Sci. 92:41374144. doi:10.2527/jas.2014-7783.

Kuran, M., J. S. M. Hutchinson, and P. J. Broadbent. 1996. The response of bovine granulosa cells to different gonadotrophins in culture. Anim. Reprod. Sci. 45:1-12. doi:10.1016/S03784320(96)01575-8.

Marques, R. S., R. F. Cooke, C. L. Francisco, and D. W. Bohnert. 2012. Effects of 24-h transport or 24-h feed and water deprivation on physiologic and performance responses of feeder cattle. J. Anim. Sci. 90:5040-5046. doi:10.2527/jas.2012-5425.
Meneghetti, M., O. G. Sá Filho, R. F. G. Peres, G. C. Lamb, and J. L. M. Vasconcelos. 2009. Fixed-time artificial insemination with estradiol and progesterone for $B$. indicus cows I: Basis for development of protocols. Theriogenology. 72:179-189. doi:10.1016/j.theriogenology.2009.02.010.

Peter, A. T., W. T. K. Bosu, and R. J. DeDecher. 1989. Suppression of preovulatory luteinizing hormone surges in heifers after intrauterine infusions of Escherichia coli endotoxin. Am. J. Vet. Res. 50:368-373.

Sá Filho, O. G., M. Meneghetti, R. F. Peres, G. C. Lamb, and J. L. Vasconcelos. 2009. Fixed-time artificial insemination with estradiol and progesterone for Bos indicus cows II: Strategies and factors affecting fertility. Theriogenology. 72:210-218. doi:10.1016/j.theriogenology.2009.02.008.

Van Engen, N. K., M. L. Stock, T. Engelken, R. C. Vann, L. W. Wulf, L. A. Karriker, W. D. Busby, J. Lakritz, A. J. Carpenter, B. J. Bradford, W. H. Hsu, C. Wang, and J. F. Coetzee. 2014. Impact of oral meloxicam on circulating physiological biomarkers of stress and inflammation in beef steers after long-distance transportation. J. Anim. Sci. 92:498-510. doi:10.2527/jas.2013-6857.

von Keyserlingk, M. A. G., and D. M. Weary. 2007. Maternal behaviour in cattle: A review. Horm. Behav. 52:106-113. doi:10.1016/j.yhbeh.2007.03.015.

Vasconcelos, J. L. M., O. G. de Sá Filho, and R. F. Cooke. 2014. Impacts of reproductive technologies on beef production in South America. Adv. Exp. Med. Biol. 752:161-180. doi:10.1007/978-1-4614-8887-3 8.

Wagner, J. J., K. S. Lusby, J. W. Oltjen, J. Rakestraw, R. P. Wettemann, and L. E. Walters. 1988. Carcass composition in mature Hereford cows: Estimation and effect on daily metabolizable energy requirement during winter. J. Anim. Sci. 66:603-612.

Whisnant, C. S., T. E. Kiser, and F. N. Thompson. 1985. Effect of calf removal on serum luteinizing hormone and cortisol concentrations in beef cows. Theriogenology 24:119-125. doi:10.1016/0093-691X(85)90217-1.

Williams, C. Y., T. G. Harris, D. F. Battaglia, C. Viguie, and F. J. Karsch. 2001. Endotoxin inhibits pituitary responsiveness to gonadotropin-releasing hormone. Endocrinology 142:1915-1922.

Williams, G. L., F. Talvera, B. J. Petersen, J. D. Kirsch, and J. E. Tilton. 1983. Coincident secretion of FSH and LH in early postpartum beef cows: Effects of suckling and low-level increases in systemic progesterone. Biol. Reprod. 29:362-373. doi:10.1095/biolreprod29.2.362. 